\title{
Mechanical chest compressions for cardiac arrest in the cath-lab: when is it enough and who should go to extracorporeal cardio pulmonary resuscitation?
}

\author{
Bjarne Madsen Hardig ${ }^{1 *}$ (D) Karl B. Kern² and Henrik Wagner ${ }^{1}$
}

\begin{abstract}
Background: Treating patients in cardiac arrest (CA) with mechanical chest compressions (MCC) during percutaneous coronary intervention (PCl) is now routine in many coronary catheterization laboratories (cath-lab) and more aggressive treatment modalities, including extracorporeal CPR are becoming more common. The cath-lab setting enables monitoring of vital physiological parameters and other clinical factors that can potentially guide the resuscitation effort. This retrospective analysis attempts to identify such factors associated with ROSC and survival.

Methods: In thirty-five patients of which background data, drugs used during the resuscitation and the intervention, $\mathrm{PCI}$ result, post ROSC-treatment and physiologic data collected during CPR were compared for prediction of ROSC and survival.

Results: Eighteen (51\%) patients obtained ROSC and 9 (26\%) patients survived with good neurological outcome. There was no difference between groups in regards of background data. Patients arriving in the cath-lab with ongoing resuscitation efforts had lower ROSC rate ( $22 \%$ vs $53 \% ; p=0.086$ ) and no survivors ( $0 \%$ vs $50 \%, p=0.001)$. CPR time also differentiated resuscitation outcomes (ROSC: 18 min vs No ROSC: 50 min; $p=0.007$ and Survivors: 10 min vs No Survivors: $45 \mathrm{~min} ; \mathrm{p}=0.001)$. Higher arterial diastolic blood pressure was associated with ROSC: $30 \mathrm{mmHg}$ vs No ROSC: $19 \mathrm{mmHg}$; $p=0.012$ ).

Conclusion: Aortic diastolic pressure during CPR is the most predictive physiological parameter of resuscitation success. Ongoing CPR upon arrival at the cath-lab and continued MCC beyond 10-20 min in the cath-lab were both predictive of poor outcomes. These factors can potentially guide decisions regarding escalation and termination of resuscitation efforts.
\end{abstract}

Keywords: Cardiac arrest, Mechanical CPR, Cath-lab, PCI

\section{Background}

Increasing interest to treat the underlying cause of cardiac arrest (CA) during resuscitation efforts has evolved since the first extended case series described the use of mechanical chest compressions (MCC) during refractory CA in the coronary catheterization laboratory (cath-lab) 8 years ago [1-5]. This treatment option has led to further studies treating refractory CA in the cath-lab setting [6]. Treatment with extracorporeal cardio pulmonary resuscitation (ECPR) has further developed this field, but also includes patients

\footnotetext{
* Correspondence: bjarne.madsenhardig@gmail.com

'Department of Cardiology, Lund University, 22242 Lund, Sweden Full list of author information is available at the end of the article
}

who experience $\mathrm{CA}$ outside the cath-lab setting, where early experience shows good outcome [4-7]. Some of these studies has been made as case series [5], ongoing randomized controlled trials (Prague NCT01511666), (Maastricht NCT03101787) (British Columbia NCT02832752) and other organizations have implemented this as a clinical routine [6]. In our early experience we observed that resuscitation in the cath-lab during simultaneous PCI vastly deviated from the normal ALS-algorithm recommended by guidelines. This demanded adjustments to the ALSalgorithms to be suitable for resuscitation efforts during simultaneous PCI, such as delaying further defibrillation attempts until coronary reperfusion is accomplished. These

(c) The Author(s). 2019 Open Access This article is distributed under the terms of the Creative Commons Attribution 4.0 International License (http://creativecommons.org/licenses/by/4.0/), which permits unrestricted use, distribution, and reproduction in any medium, provided you give appropriate credit to the original author(s) and the source, provide a link to the Creative Commons license, and indicate if changes were made. The Creative Commons Public Domain Dedication waiver (http://creativecommons.org/publicdomain/zero/1.0/) applies to the data made available in this article, unless otherwise stated. 
adjustments were recognized by resuscitation guidelines in 2015 [8]. The cath lab setting enables monitoring of physiological parameters and thus a more individual patient tailored treatment can be given [9]. Adequate levels of physiological parameters have previously been correlated with successful return of spontaneous circulation (ROSC) [7-13]. This retrospective analysis therefore explores multiple factors to identify which might be associated with ROSC and survival to understand which patients will do well with MCC alone and which may need ECPR.

\section{Methods}

At the university hospital in Lund Sweden, a tertiary hospital with PCI facilities 24/7, 75 patients suffering CA in the cath-lab have been treated and evaluated in the cathlab setting from January 1, 2004 to April 9, 2013 where outcome data that has been published $[1,5]$. Detailed information regarding important clinical parameters were collected for 35 patients where, eight patients (23\%) suffered CA out of hospital and arrived to the cath-lab with ongoing resuscitation efforts and 27 (77\%) suffered CA during the intervention (with approval from the local ethical board in Lund (667/2009)). To evaluate the aspects of important confounding factors related to ROSC and survival, patients were divided into four different groups; data from patients that obtained ROSC were compared to data from those not obtaining ROSC and data for survivors were compared to non- survivors. The following data were collected and compared: Background data including concomitant diseases, reason to be admitted to the cath-lab i.e. the diagnosis, culprit lesion, rhythm causing the CA, drugs used during the resuscitation, anticoagulants used during the intervention, PCI-results, post ROSC-treatment and physiologic data collected during CPR. These data were compared for prediction of ROSC and survival differences.

\section{Statistics}

Background parameters, resuscitation related parameters, PCI treatment variables and post ROSC treatment variables were presented as percentages for categorical data, while mean and standard deviation were used for continuous data, as appropriate. $P$-values for differences between the two groups was calculated using Fisher's exact test for categorical data and using Mann-Whitney $\mathrm{U}$ test for numerical parameters. A P-value of $<0.01$ was considered to indicate a significant difference as no other adjustment for multiple comparison was made.

\section{Results}

Eighteen (51\%) of the patients gained ROSC and 9 (26\%) patients survived with good neurological outcome. There was no difference between those that obtained ROSC and those that did not nor when comparing data from survivors and non-survivors in regards of background data including concomitant diseases, reason for admission to the cath-lab i.e. cardiac diagnosis, culprit lesion, rhythm causing the arrest (Table 1). Both ROSC patients and surviving patients had VF/VT $(N=7(20 \%))$, asystole $(N=4(11 \%))$, bradycardia $(\mathrm{N}=7(20 \%))$ and pulseless electric activity $(N=17(49 \%))$ as the initiating rhythm for CA (Fig. 1). Fewer ROSC patients and surviving patients received epinephrine and the amount given was lower (Table 1). The CPR time was shorter for those that gained ROSC and survivors (Table 1). Those that arrived at the cath-lab with ongoing CPR had lower chance of obtaining ROSC (22\% compared to $53 \%$ if the CA occurred in the cath-lab, not significant $P=0.086$ ). None of the patients survived when resuscitation was ongoing when they were admitted to the cath-lab (Table 1). There was a significant higher median arterial early diastolic blood pressure among those that obtained ROSC compared to non-ROSC patients $(30(22-40) \mathrm{mmHg}$ vs 19 (14-28) $\mathrm{mmHg}, P=0.012)$, but only a trend to higher end diastolic and mean arterial pressures (Table 1), these numerical higher values were also seen among surviving patients however these were not significant (Table 1).

\section{Discussion}

This analysis, although admittedly limited by the small number of patients, shows that it is possible to collect and monitor several important parameters that might be predictors of ROSC and survival during treatment of refractory CA patients in the cath-lab setting. The collected data generated a large amount of information from each patient in aspects of background data, concomitant diseases, cause of the CA, circulatory state, rhythm at the event of CA, type of chest compressions, drugs given during advanced life support (ALS), physiologic parameters during ALS, culprit vessel, $\mathrm{PCI}$-outcome, ROSC and survival. From these data several useful parameters emerged, namely if the patient arrived at the cath-lab with ongoing CPR and the length of time $\mathrm{MCC}$ were required in the cath-lab to establish ROSC. Both these clinical factors were associated with ultimately poor outcomes. No patient survived who arrived at the cath-lab with ongoing CPR, while the median time of MCC in the cath-lab for those who did survive was 10 min versus $45 \mathrm{~min}$ for those patients not surviving.

Predictive parameters have been previously reported for cardiac arrest. These include co-morbid conditions (concomitant diseases, culprit vessel, circulatory state) that are known to affect outcome for STEMI and following PCI $[14,15]$ and the cause of the CA in these specific cases are often known (coronary artery occlusion) but also, parameters important for assessing CPR-quality [7, 14-16], parameters important for the assessment of blood pressure and perfusion that might be useful to predict ROSC and survival 


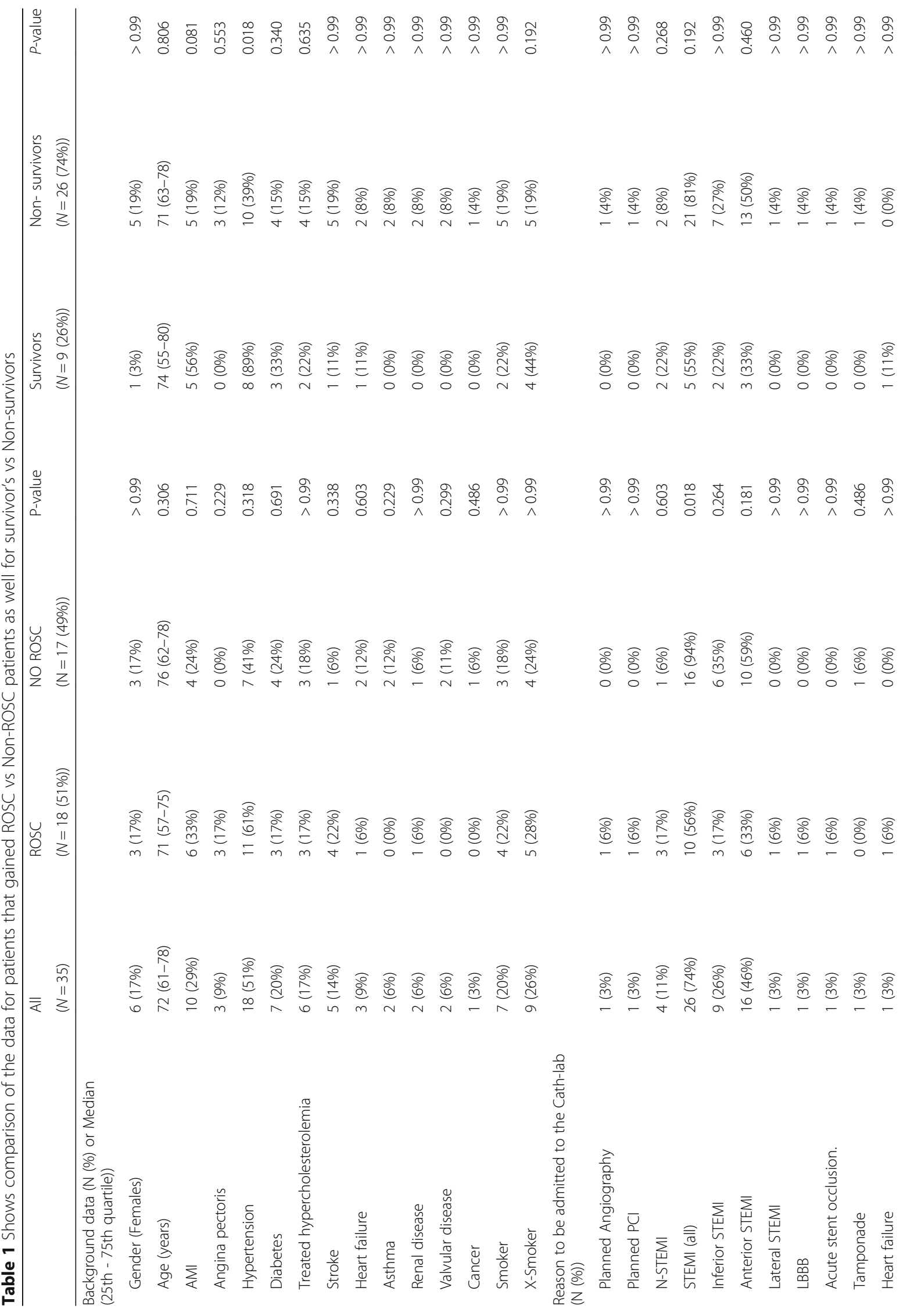




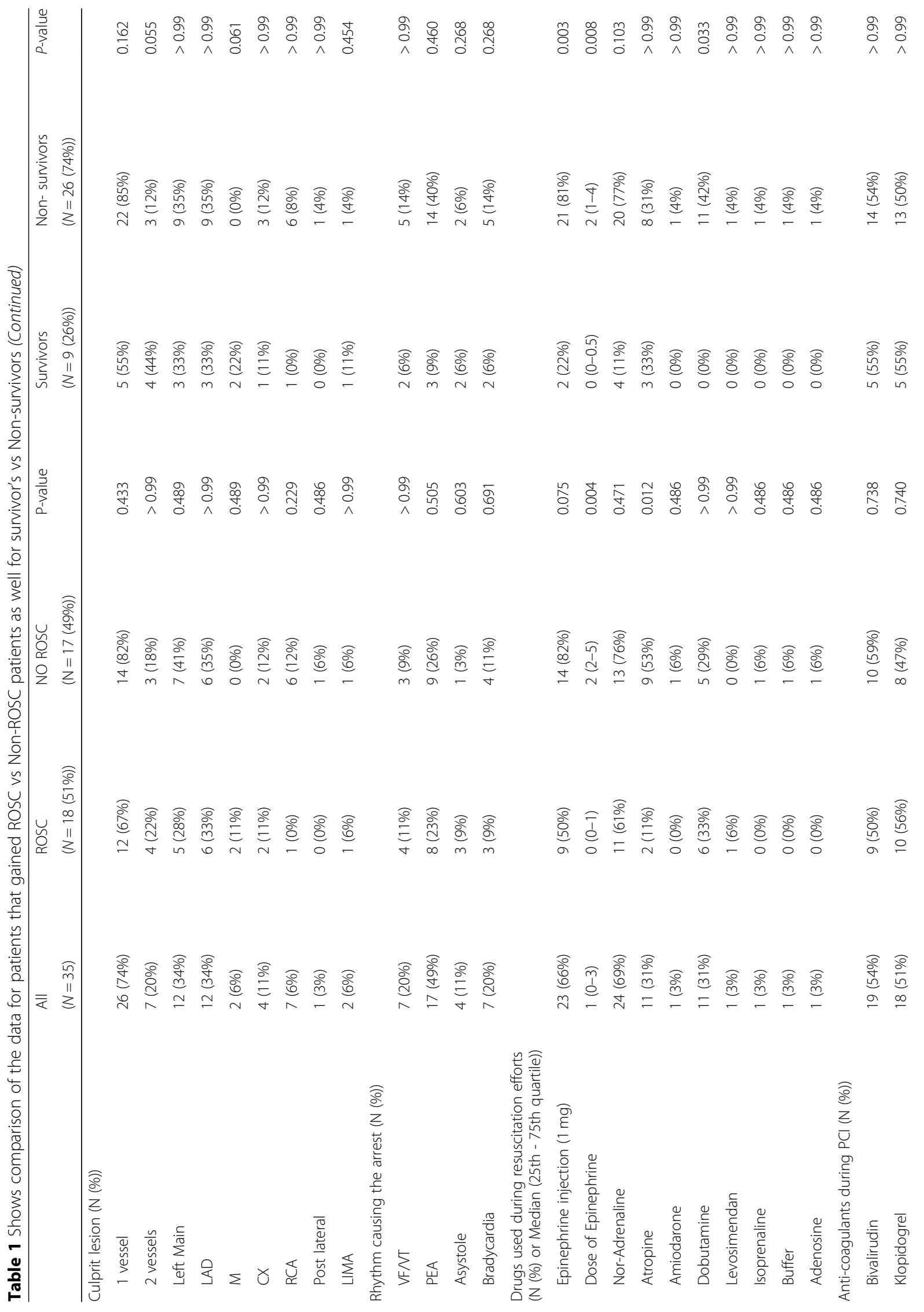




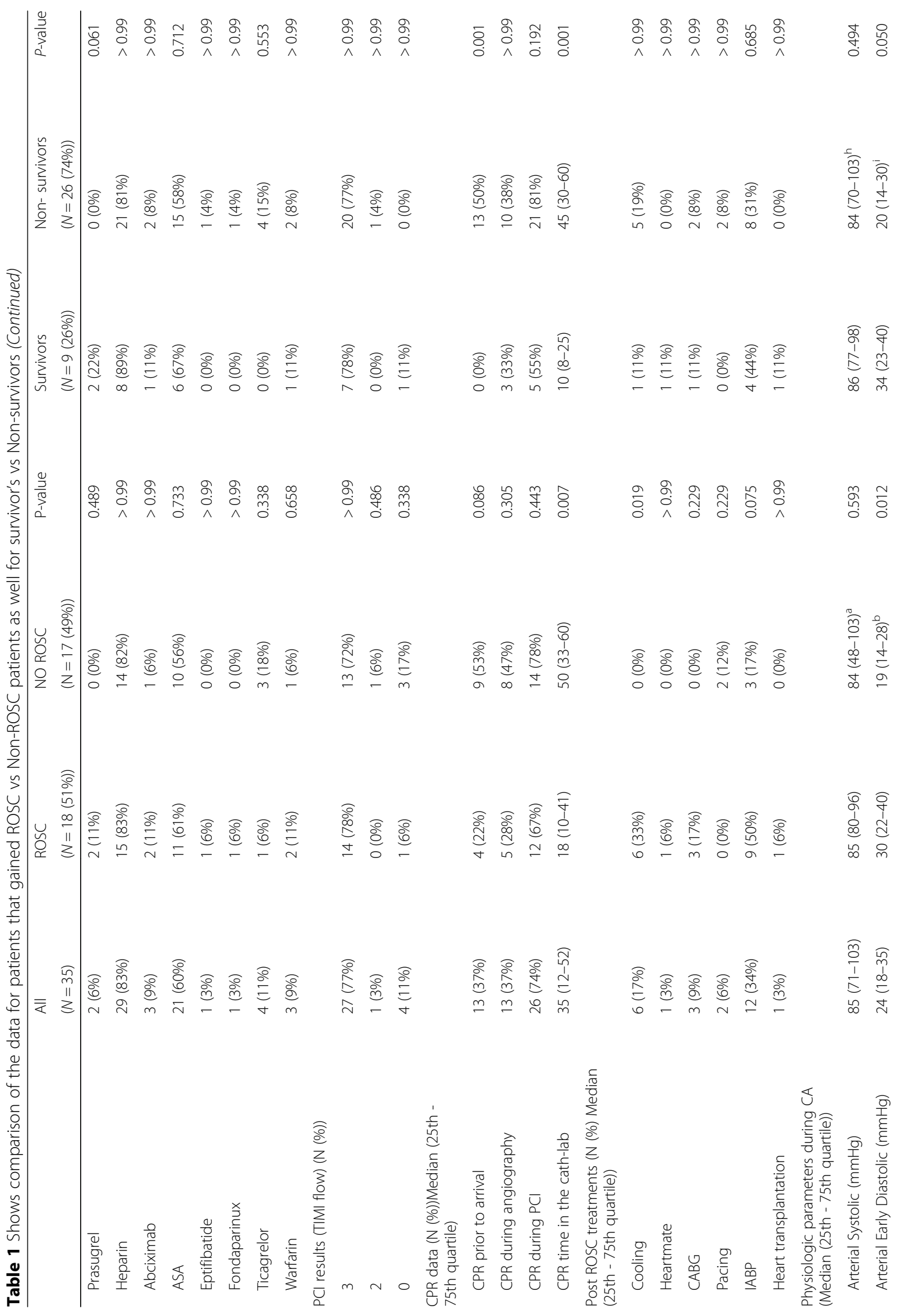




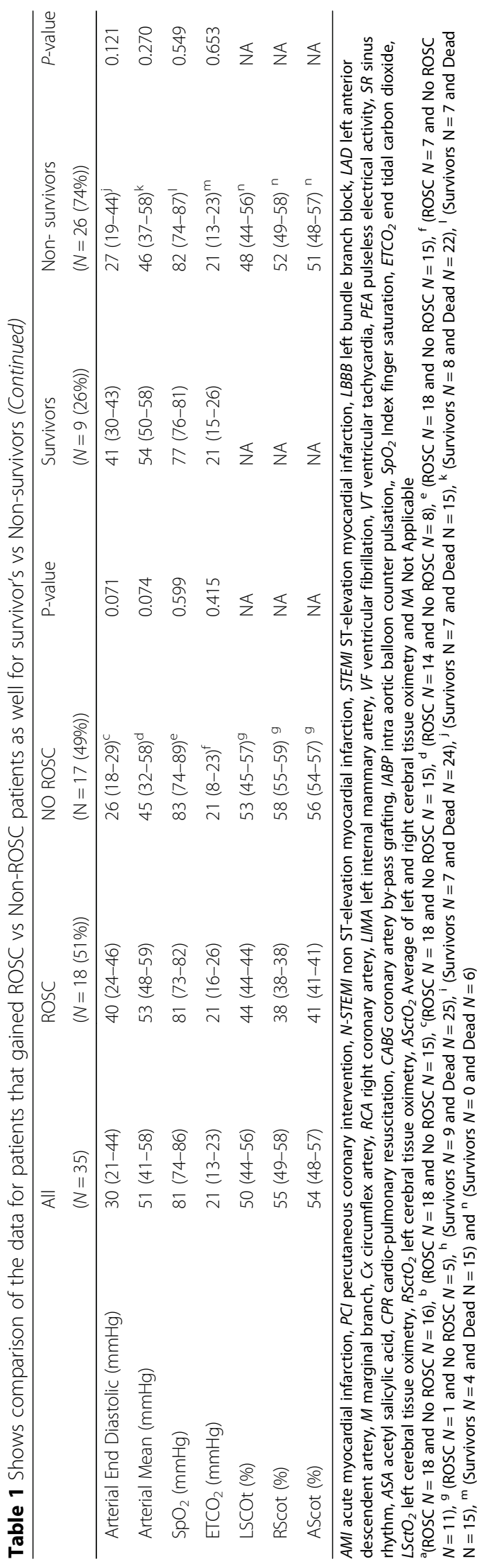




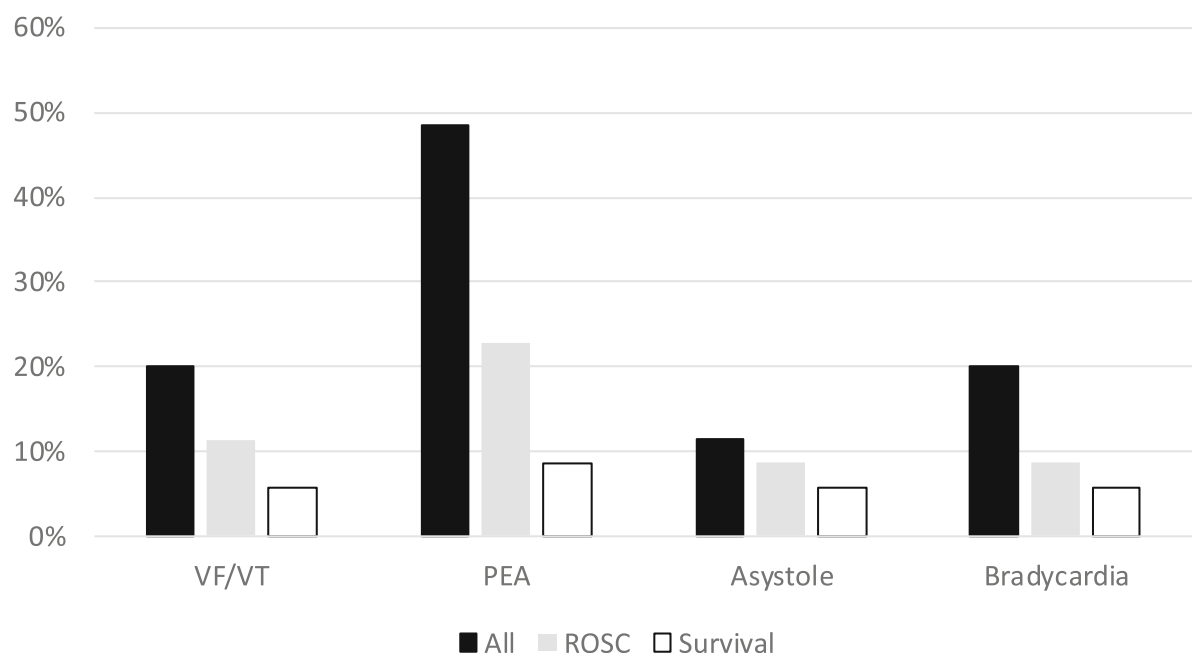

Fig. 1 Shows the distribution of rhythm causing the arrest and its relation to ROSC and survival (VFNT = ventricular fibrillation/ventricular tachycardia, PEA = pulseless electrical activity)

$[10-13,17,18]$, factors as rhythm at the time of the CA [18], use of vasoactive drugs [19-22], duration of ALS, TIMI-flow and post-ROSC treatment [23], are also known factors that can affect outcome after CA and feasible to collect.

In this limited series of cath-lab cardiac arrest, initial rhythm did not predict outcome. One parameter reported in series of ECPR patients that was not included in our database is arterial lactate levels, which has appeared to be markedly different between survivors and non-survivors [21].

The median cath-lab CPR time among the nonsurviving patients (45 min (30-60) in this series, is in the same range as that seen as unfavourable in some ECPR cohort reports. Lamhaut and collaborators showed a significant increase in survival when the decision point for ECPR was set at $20 \mathrm{~min}$ of ALS, from the prior $30 \mathrm{~min}$ [24]. This finding of a finite time limit of MCC in the cath-lab of 10 to $20 \mathrm{~min}$ to achieve good outcomes suggests that if such a time is approaching the decision for escalating therapy to ECPR must be made before it is too late. Prolonging the period of MCC support too long can impair the chances for a good outcome [1].

In the present case series, patients with both shockable and non-shockable rhythms achieved long-term survival with MCC (Fig. 1), whilst most studies using extracorporeal cardio pulmonary resuscitation have been restricted to patients in refractory VF/VT since these CA are assumed to be of a cardiac origin. However, our data shows that this assumption might not be correct and some patients with non-shockable rhythms may also respond to MCC while the cause of their cardiac arrest is treated in the cath lab.

\section{Limitation}

The major limitation is the small number of patients in this case series. Further study with additional patients could better define other important factors regarding the usefulness of MCC in the cath-lab and which patients should go on to ECPR. Another way to overcome this limitation, we suggest collaboration with other cath-labs implementing similar treatment algorithms and monitoring to be able to collect a sufficient number of patients for these rare cases.

\section{Conclusion}

When a cardiac arrest occurring in the cath-lab aortic pressure should be monitored during the resuscitation efforts striving for at least $30 \mathrm{mmHg}$ in diastolic values. If this cannot be achieved escalation of therapy to ECPR should be considered. This decision should be made within the first 10-20 min of resuscitation efforts in the cath-lab, as longer periods are associated with a decrease in survival. Finally, cardiac arrest occurring before and still requiring resuscitation efforts upon arrival at the cath-lab should be considered for ECPR as continuing chest compressions alone resulted in poor outcome.

\section{Abbreviations}

ALS: Advanced life support; CA: Cardiac arrest; CPR: Cardio- pulmonary resuscitation; ECPR: Extracorporeal cardio pulmonary resuscitation; MCC: Mechanical chest compressions; PCl: Coronary catheterization laboratories; ROSC: Return of spontaneous circulation; TIMI: Thrombolysis in myocardial infarction; VF: Ventricular fibrillation; VT: Ventricular tachycardia

\section{Publisher's Note}

Springer Nature remains neutral with regard to jurisdictional claims in published maps and institutional affiliations. 


\section{Authors' contributions}

$\mathrm{BMH}$ and $\mathrm{HW}$ : collect, analysed and interpreted all the patient data in this manuscript, $\mathrm{BMH}$ made the first draft of the manuscript, tables and figure. All three authors (BMH, KBK and $\mathrm{HW}$ ) worked together on the analyse and the interpretations of the data and manuscript until it reached its final stage as it is submitted. All authors (BMH, KBK and HW) read and approved the final manuscript.

\section{Funding}

Funding's to perform this study comes from the authors affiliated universities in the form of salary. Funding's for publications cost were given by the producer of the LUCAS chest compression system (Stryker/Jolife AB, Lund, Sweden), but the company had no influence on the design of this study nor on the reporting of the results, interpretation, analysis or the content of manuscript.

\section{Availability of data and materials}

The datasets used and/or analysed during the current study are available from the corresponding author and author HW on reasonable request.

\section{Ethics approval and consent to participate}

This study has been performed under the approval from the Swedish Ethical Review Authority at Lund University (approval number: 667/2009). Both verbal and written information and consent were given and taken from the surviving patients. If the patient did not survive the event, verbal and written information and consent were given and taken from the closest relative. Written consent to use the data was thus given from all patients in this study.

\section{Consent for publication}

The approval from the Swedish Ethical Review Authority at Lund University (approval number: 667/2009), included a consent for publication and each patient or relative has approved this in their signed written consent.

\section{Competing interests}

Bjarne Madsen Hardig was earlier employed by Physio-Control/Lund, a part of Stryker, the manufacturer producing the LUCAS chest compression device. Karl B Kern is a compensated member of the Science Advisory Board for Physio-Control, now a part of Stryker, and has received investigator-initiated grant funding from Physio-Control. Henrik Wagner has received lecture fees from Jolife AB Sweden.

\section{Author details}

${ }^{1}$ Department of Cardiology, Lund University, 22242 Lund, Sweden. ${ }^{2}$ Sarver Heart Center, University of Arizona, Rm. 005145, Tucson, AZ 85724, USA.

Received: 22 February 2019 Accepted: 17 May 2019

Published online: 03 June 2019

\section{References}

1. Wagner H, Terkelsen CJ, Friberg H, Harnek J, Kern K, Lassen JF, Olivecrona GK. Cardiac arrest in the catheterisation laboratory: a 5-year experience of using mechanical chest compressions to facilitate $\mathrm{PCl}$ during prolonged resuscitation efforts. Resuscitation. 2010;81:383-7. https://doi.org/10.1016/j. resuscitation.2009.11.006

2. Larsen Al, Hjørnevik AS, Ellingsen CL, Nilsen DW. Cardiac arrest with continuous mechanical chest compression during percutaneous coronary intervention. A report on the use of the LUCAS device. Resuscitation. 2007; 75:454-9.

3. Larsen Al, Hjørnevik AS, Ellingsen CL, Nilsen DW. Coronary blood flow and perfusion pressure during coronary angiography in patients with ongoing mechanical chest compression: a report on 6 cases. Resuscitation. 2010;81: 493-7. https://doi.org/10.1016/j.resuscitation.2010.02.002.

4. Wagner H, Madsen-Hardig B, Rundgren M, Harnek J, Gotberg M, Olivecrona GK. Cerebral oximetry during prolonged cardiac arrest and percutaneous coronary intervention : a report on five cases. ICU Dir. 2013;4:22.

5. Wagner H, Hardig BM, Rundgren M, Zughaft D, Harnek J, Götberg M, Olivecrona GK. Mechanical chest compressions in the coronary catheterization laboratory to facilitate coronary intervention and survival in patients requiring prolonged resuscitation efforts. Scand J Trauma Resusc Emerg Med. 2016;24:4. https://doi.org/10.1186/s13049-016-0198-3.

6. Venturini JM, Retzer E, Estrada JR, Friant J, Beiser D, Edelson D, Paul J, Blair J, Nathan S, Shah AP. Mechanical chest compressions improve rate of return of spontaneous circulation and allow for initiation of percutaneous circulatory support during cardiac arrest in the cardiac catheterization laboratory. Resuscitation. 2017;115:56-60. https://doi.org/10.1016/j. resuscitation.2017.03.037.

7. Steen S, Liao Q, Pierre L, Paskevicius A, Sjöberg T. Evaluation of LUCAS, a new device for automatic mechanical compression and active decompression resuscitation. Resuscitation. 2002;55:285-99.

8. Redding JS. Abdominal compression in cardiopulmonary resuscitation. Anesth Analg. 1971;50:668-75.

9. Paradis NA, Martin GB, Rivers EP, Goetting MG, Appleton TJ, Feingold M, Nowak RM. Coronary perfusion pressure and the return of spontaneous circulation in human cardiopulmonary resuscitation. JAMA. 1990;263:1106-13.

10. Jin X1, Weil MH, Tang W, Povoas H, Pernat A, Xie J, Bisera J. End-tidal carbon dioxide as a noninvasive indicator of cardiac index during circulatory shock. Crit Care Med. 2000;28:2415-9.

11. Grmec S, Klemen P. Does the end-tidal carbon dioxide (EtCO2) concentration have prognostic value during out-of-hospital cardiac arrest? Eur J Emerg Med. 2001;8(4):263-9.

12. Moon SW, Lee SW, Choi SH, Hong YS, Kim SJ, Kim NH. Arterial minus endtidal $\mathrm{CO} 2$ as a prognostic factor of hospital survival in patients resuscitated from cardiac arrest. Resuscitation. 2007;72:219-25.

13. Griffin $\mathrm{M}$, Cooney C. Pulse oximetry during cardiopulmonary resuscitation. Anaesthesia. 1995;50:1008.

14. Sutton RM, French B, Nishisaki A, Niles DE, Maltese MR, Boyle L, Stavland M, Eilevstjønn J, Arbogast KB, Berg RA, Nadkarni VM. American Heart Association cardiopulmonary resuscitation quality targets are associated with improved arterial blood pressure during pediatric cardiac arrest. Resuscitation. 2013;84: 168-72. https://doi.org/10.1016/j.resuscitation.2012.08.335.

15. Hamrick JL, et al. Efficacy of chest compressions directed by end-tidal $\mathrm{CO} 2$ feedback in a pediatric resuscitation model of basic life support. J Am Heart Assoc. 2014;3(2):e000450. https://doi.org/10.1161/JAHA.113.000450.

16. Hamrick JL, Hamrick JT, Lee JK, Lee BH, Koehler RC, Shaffner DH. Physiologic monitoring of CPR quality during adult cardiac arrest: a propensity-matched cohort study. Resuscitation. 2016;106:76-82. https://doi.org/10.1016/j. resuscitation.2016.06.018.

17. Pokorná M, Necas E, Kratochvíl J, Skripský R, Andrlík M, Franek O. A sudden increase in partial pressure end-tidal carbon dioxide (P (ET)CO(2)) at the moment of return of spontaneous circulation. J Emerg Med. 2010;38:61421. https://doi.org/10.1016/j.jemermed.2009.04.064.

18. Eckstein M, Hatch L, Malleck J, McClung C, Henderson SO. End-tidal CO2 as a predictor of survival in out-of-hospital cardiac arrest. Prehosp Disaster Med. 2011;26(3):148-50. https://doi.org/10.1017/S1049023X11006376.

19. Olasveengen TM, Sunde K, Brunborg C, Thowsen J, Steen PA, Wik L. Intravenous drug administration during out-of-hospital cardiac arrest: a randomized trial. JAMA. 2009;302:2222-9. https:/doi.org/10.1001/jama.2009.1729.

20. Warren SA, Huszti E, Bradley SM, Chan PS, Bryson CL, Fitzpatrick AL, Nichol G. American Heart Association's get with the guidelines-resuscitation (National Registry of CPR) investigators. Adrenaline (epinephrine) dosing period and survival after in-hospital cardiac arrest: a retrospective review of prospectively collected data. Resuscitation. 2014;85:350-8. https://doi.org/10. 1016/j.resuscitation.2013.10.004.

21. Perkins GD, Ji C, Deakin CD, Quinn T, Nolan JP, Scomparin C, Regan S, Long J, Slowther A, Pocock H, JJM B, Moore F, Fothergill RT, Rees N, O'Shea L, Docherty M, Gunson I, Han K, Charlton K, Finn J, Petrou S, Stallard N, Gates $\mathrm{S}$, Lall R. PARAMEDIC2 collaborators. A randomized trial of epinephrine in out-of-hospital cardiac arrest. N Engl J Med. 2018;379:711-21. https://doi. org/10.1056/NEJMoa1806842.

22. Lindner $\mathrm{KH}$, Ahnefeld FW. Comparison of epinephrine and norepinephrine in the treatment of asphyxial or fibrillatory cardiac arrest in a porcine model. Crit Care Med. 1989;17:437-41.

23. Bernard SA, Gray TW, Buist MD, Jones BM, Silvester W, Gutteridge G, Smith K. Treatment of comatose survivors of out-of-hospital cardiac arrest with induced hypothermia. N Engl J Med. 2002;346:557-63.

24. Lamhaut L, Hutin A, Puymirat E, Jouan J, Raphalen JH, Jouffroy R, Jaffry M, Dagron C, An K, Dumas F, Marijon E, Bougouin W, Tourtier JP, Baud F, Jouven X, Danchin N, Spaulding C, Carli P. A pre-hospital extracorporeal cardio pulmonary resuscitation (ECPR) strategy for treatment of refractory out hospital cardiac arrest: An observational study and propensity analysis. Resuscitation. 2017;117:109-17. https://doi.org/10.1016/j.resuscitation.2017. 04.014 . 